UDC $1 / 14$

Lin TAO,

Haijun TANG,

Mingzhuo ZOU

\title{
ON THE COMPLEX EMOTION: BE PHYSIOLOGICAL, COGNITIVE OR SITUATED?*
}

\begin{abstract}
The topic emotion in traditional philosophy is discussed fragmentarily. And in recent years, there are two important approaches to analyze emotions, namely neo-Jamesianism and cognitive theory of emotion. Neo-Jamesians identify emotions with states of bodily arousal, which is determined by the nerve and occurs because of the feelings of bodily changes. And the cognitivists identify emotions with representations of evaluative judgments, which is regarded as propositional content accepted or affirmed by their subjects. Besides, the situated theory suggests we should expand our attention to the cultural and social environment in which emotions are moulded.
\end{abstract}

Keywords: emotion; cognition.

Humankind has been tirelessly seeking for the certain knowledge about the world, society and human being by itself since classical period. In ancient Greece, philosophers put forward different hypotheses in which the world is made of something, such as Thales' water, Anaximander's apeiron, Anaximenes' air, Heraclitus' fire, Democritus' atom, Pythagoras' numbers. Different from those predecessors, Aristotle focuses on human thinking modes, such as propositions, judgments and ratiocination, tries to summarize the rules of deduction and form a universal model in order to provide reliable tools for certain knowledge. Anyways, Ontological introspection did not resolve the debate and not supply the reliability of knowledge until early modern period.

* This study was funded by the Ministry of Education of PRC, the fund number is 13JDXF008.
Francis Bacon resorts to the experimental methods and induction to seek for the general rules from individual fact, by which he believes that man can acquire universal knowledge. In order to resolve the ontological debate, Descartes attempts to find the only solid foundation of the existence of the world by transferring the focus from what is the world to how do we know the world, as a result, he brings an epistemological turn which urges seeking for the knowledge outwards. In the early of last century, the philosophers began to analyze language in order to clarify the ambiguity of daily language and resolve the philosophical questions, by which some new methodologies for knowledge emerged. In recent years, mind as thinking structure of language has become a new hot topic. Then some other topics related to mind, such as cognition and emotion, are increasingly in the spotlight. 
Plato writes in Theaetetus that philosophy begins with the Wonder; Aristotle also asserts the same in Metaphysics. Wonder is an emotion; thinking about the essence of the world and pursuing certain knowledge, both are original task of philosophy. The two sages have been keenly aware of the stimulating effects of emotion on cognitive activities. So, what an emotion is, how emotion functions in activities of cognition and the relationship between emotion and cognition, etc., many questions need to be discussed.

\section{Emotion in Traditional Philosophy}

The philosophical discussion on emotion can be traced back to Plato's division of the soul into three parts: reason, passion and desire. In Plato's view, the part of the soul for thinking and inference is reason, the part for perceiving anger is passion, and the turbulent and irrational part for perceiving love, hungry and thirst is desire, which is accompanied by satisfaction and happiness (Plato, 2003, p. 418). Those three parts of the soul correspond to the three virtues of wisdom, bravery, and temperance. The soul can be in harmony if reason is to maintain wisdom, passion is to achieve bravery and desire is to be tempered, and a person with that harmonious soul owns the virtue of justice and then can become a righteous person. In Aristotle's encyclopedic writing, there are also certain chapters to discuss emotions. In his Rhetoric, he defines emotion as that emotions include all moods that make people change their mind, make judgments and then give them distress or pleasure (Aristotle, 2005, p. 107). He argues that there are only two kind of the feeling of an emotion: pleasure or distress. Pleasure comes from innermost desires. The way to obtain the sense of pleasure comes from feelings about the present, memories of the past and expectations of the future. The Stoicism discusses emotions from a negative perspective, and talk about various types of good or evil motives, desires and tendencies in the term impulse. The various impulses constitute different beliefs, and emotions, which are divided into four types: desire, worry, happiness and pain (other types of emotions, such as jealousy, regret and mourning, etc., are only their subsets), are the components of impulses (Graver, 2007).

Descartes believes that emotions which include feeling, perception, desires and beliefs, are produced by animal soul. Emotion is not only the feeling of the body, but also the experience of the soul. He thinks that there are six major passions: surprise, love, hatred, desire, happiness and sadness, and that other passions belong to those six passions (Descartes, 2015). Spinoza treats emotion as one of the forms of thought, and there are three basic emotions: happiness, pain and desire, and other emotions are combined or derived from those three types (Spinoza, 1997). Hume regards emotion as one of the three basic roles of human nature and argues that the main motive force of human mind comes from happiness or pain, and that emotions fundamentally are derived from the body's happiness and pain, which produce desires and will and then make mind has prone or offensive activities. Hume further discusses from emotions to morality, and thinks that emotion is the true essence of human social existence and morality (Hume, 2015). Under the influence of Hume, Kant also divide human nature into three aspects: cognitive ability, emotional ability, and orectic ability. Kant believes that basic emotions has two types: the happy emotion and the unpleasant emotion, which origin from the pleasant or painful feelings of the body, and which 
respectively contain two types: perceptual and intellectual emotions, in which the perceptual emotion is expressed through the body or imagination and intellectual emotion is achieved through the manifested concept or idea (Kant, 2005).

Some of above arguments of emotions agree with that, to some extent, emotion has cognitive ability. The argument that emotion has cognitive ability can be traced back to those of Aristotle and the Stoicism. Aristotle points out that emotions can make people change their opinions and make different judgments. $\mathrm{He}$ thinks there are three indispensable conditions for triggering certain emotion: the first is the mood before the occurrence of certain emotions, the second is the object that an emotion refers to, and the third is the cause of an emotion (Aristotle, 2005). Aristotle's definition of the condition of triggering an emotion, which is early version of intentional analysis of the content of an emotion, is quite insightful. The Stoicism regards emotion as a mixture of various types of good or evil motives, desires, tendencies, or beliefs, whose intentional object has certain qualities of good or evil, or is composed of beliefs lacking certain knowledge. The Stoicism's emotion theory has a strong cognitive colour, we can find that the stoicism treats emotions as the types of judgments and considers that each emotion is essentially a judgment about the current or potential state of affairs. Seneca and Chrysippus, for example, believe that emotion is a judgment about the world and about the state of man in the world. In their opinion, the world in which people lived has been out of their control and out of their expectation. Through emotions, they could intensify their actual feelings and expectation to the world and be released spiritually. But it is very difficult to finally get rid of the tragic situa- tions; emotions can only provisionally delay misfortune and setbacks. Therefore, emotions are just judgments with false concept. In the view of the Stoicism, emotions are generated with purpose and they have propositional contents which always expresses certain objects carries a certain kind of affirmation or belittling of value. So emotions have a corresponding effect on behavior. The Stoicism discusses some of the judgments that constitute some emotions, such as anger in moral judgments, the fragility of love, and anxiety about the feel of self-centered security (Graver, 2007). Spinoza is considered to be a modern version of the Stoicism. He tends to think that emotion has cognitive function and regards emotion as a form of thought that makes us painful and frustrated (this is similar to the Stoicism); The nature of mind consists of the correct idea and the incorrect idea (Spinoza also called the clear concept and the confusing concept), the correct concept, which is associated with active emotions, leads to the initiative of mind. And incorrect ideas induce the passiveness of mind, which is associated with the passive emotion (Spinoza, 1997, pp. 104-105). Most emotions, which are based on incorrect idea and bring people pain, depression and weakness, are passive reactions to the world's expectations. Active emotions are based on correct concept, show the true nature and enhance people's power of understanding.

\section{Is Emotion Physiological or Cognitive?}

In the past 40 years, emotion has increasingly been discussed with the study on mind and cognition. Because of the different understanding about the nature of emotion, the relationship between emotion and cognition, and the role of emotion in cognitive activities, most 
of the researchers stand on two major perspectives on emotion, which are neo-Jamesianism and cognitive theories of emotion.

Neo-Jamesians are strongly influenced by Darwin and William James, therefore accept Darwin's evolutionism and William James' assertion that emotions are the state of physical arousal and, to some extent, the opinion of the emotional commonality between man and animal. The research aim of Neo-Jamesianism is mainly the origins of emotions and it is supported by some neuroscientists and psychologists. Neo-Jamesianism appropriately explains the debates whether animals and infants have emotions, but there are some theoretical contradictions in it. At first, neo-Jamesians regard each emotion as the feeling or reaction when a series of specific behaviors and physical changes occur, so emotion would be unconscious, but it is seemingly impossible that one can unconsciously feel the physical changes. Secondly, intentionality is generally considered as the core element of an emotion which always refers to an object, neo-Jamesians actually does not deny the intentionality of emotion, different from their predecessor William James in this respect, but they potentially deny the intentionality of emotion because they think of emotion as only the by-product of bodily change. In addition, as far as the intentionality of emotion, an emotion always refers to an external object rather than physical state while the object of the feeling of physical changes refers to the physical state, so how can we identify an emotion with the feeling of physical change?

The cognitive theories of emotion are opposite with neo-Jamesianism. The theories, here we are talking about, are not from a unified school but a group with a broader class of similar cognitive emotion theories, which include those from Nico Frijda, Richard Lazarus in psychology, Robert Solomon, Mathar Nussbaum, Peter Goldie, Ronald De Sousa, Patricia Greenspan, Michael Stocker in philosophy, and some other scholars in different fields. The cognitive theories of emotion inherit and develop Aristotle's and stoicism's view that emotion may be a judgment, and some standpoints even origin from Wittgenstein and existentialism. The cognitivists agree that emotions are rational and that there is an evaluative judgment or appraisive belief in each emotion, in other words, emotions are the cognitive state with some propositional contents. The occurrence of an emotion means one accepts some belief with specific propositional contents, even, confirms a decision or makes a choice. Thus, for the subject, emotions are controllable.

Emotions are also the intentional state of the mind. In the cognitive emotion theories, the intentionality of an emotion plays an important role, it means that an emotion is always refers to something in the world and each emotion is always the emotion involves something specific, and that the physiological feeling without intentional content is meaningless. Therefore, the cognitivists do not discuss the feelings merely related to physical change and remove the feelings from emotions. Correspondingly, emotions are outward-facing and there are always some outward signs or physical appearances with an emotion, which are externally perceptible.

The cognitive emotion theories inquire into the property and meaning of emotions. In the theories, the pattern of the occurrence of emotions is different with that of neo-Jamesianism. One encounters the outside stimuli, which trigger certain beliefs or judgments, and then an emotion happens, after that, the corresponding external physical signs and facial expression, 
which even company with action, appear. For example, when someone encounters a Komodo dragon, at first he realizes that it is dangerous, and then he feels the emotion fear with the trembling in his legs, finally he runs away.

Although the members of cognitive camp do not have same academic interest, the researchers who are labeled as cognitivists nearly all agree that the appraisive judgment, by whose content the intentionality of an emotion is explained and the meaning of an emotion is understood well, is the basic necessary element of an emotion; the cognitivists try to explain the intentional content of an emotion with generalized, succinct and universal judgments. The trigger of an emotion, whose process includes the subject of an emotion, the intentional object, the intentional content and the situation the subject is faced with, finally should be attributed to the appraisive judgments.

Now let we focus on the emotion sympathy. For example, Wang's neighbour has a car accident and he is seriously injured; Wang thinks that the undeserved misfortune should not fall on his neighbour. In this case, the referred object is the neighbour who has suffered the car accident and is injured, and the content of the proposition is that:

A. a kind man should be blessed.

B. the neighbour is a kind man.

C. the neighbour should be blessed / the neighbour should not be given the misfortune.

After Wang comes to the conclusion in his mind with the abovementioned syllogism, the emotion sympathy occurs. Here, we may discuss more. How does the subject come to the conclusion whether someone deserves misfortune or not? It depends on how much knowledge of the person who suffers misfortune the subject has and also depends on the social and cultural environment in which an emotion is generated. In this case, the unfortunate neighbour is a kind person, so Wang is very easy to belief that his neighbour does not deserve the misfortune and then realizes the emotion sympathy. Suppose the neighbour would be an evil person and get along bad with Wangs, then Wang would have the emotion gloating rather than sympathy. Suppose the kind neighbour suffers the undeserved misfortune, but it would happen during war time and there would be many persons died every day. In this case, would Wang still has the same judgments so that he would feel the emotion sympathy for his pitiful neighbour while he and other persons would experience their friends, relatives even family members died? In addition, the important factor namely the subject should take into consideration. If different subjects feel the same emotion, are there the same bases and reasons with those judgments which trigger the same emotion? That is debatable. Anyway, even though different subjects feel a same emotion, the contents of their appraisive judgments in an emotion may be completely different. In the same way, encountering a same event in different situations, the caused emotion may be different. In general, though the cognitivists put forward their own arguments, they have the same standpoint that there are appraisive judgments as basic element with each emotion.

In accordance with to which extent the cognitive theories stand for the basic view that emotion is cognitive, the camp is regarded as two subset which are those with strong cognitive perspective (such as Robert Solomon, Martha Nussbaum, etc.) and those with weak cognitive perspective (such as Peter Goldie, Ronald De Sousa, Michael Stocker, Patricia Greenspan, 
etc.) Robert Solomon developed the cognitive theory of emotion, in which he thinks that emotions are rational and emotions involve cognitive activity controlled by the subject or based on the choice of the subject (Solomon, 1993, pp. 125-131, pp. 309-310); He earlier argues the idea that emotions are evaluative judgments (Solomon, 1988). Martha Nussbaum analyzes a series of the structures of emotions (such as sympathy, love and anger). She believes that emotions are not repulsive forces and not purely spiritual impulses, but include intentionality, evaluation and beliefs which are the core element of emotions as cognitive contents and can cause the changes of emotions (Nussbaum, 2001, pp. 19-88). Richard Lazarus pays attention to emotions and stress, and their relationship with cognition; he classifies the moral appraisals in the different emotions as five core related themes: anger, fear, sadness, disgust, and happiness, with which the function of emotions and their eliciting conditions can be analyzed (Lazarus, 1991). Peter Goldie believes that the operating mechanism of emotion is overrationalized; he places emotions in the context of consciousness, feeling and imagination, discusses the role of culture and evolution in the development of the capabilities of human emotions (Goldie, 2002). Patricia Greenspan discusses emotion and practical reason, argues that emotions provide an essential basis for choices and behaviors. She does not oppose the view from evolutionism, thinks that the self-reaction of emotion and the ability of human being accurately distinguishing different emotions are based on evolutionary development. She also thinks that emotions can express evaluative judgments with the contents and attitude of propositions (Greenspan, 1993). Jon Elster explains emotions with rational choice theory, and reveals that cognition, choice and rationality are weakened by the natural material process that forms the basis of emotions and desires (Elster, 2012). Ronald De Sousa also pays attention to the rationality of emotion and the cognitive component of emotions. He thinks that emotion is a kind of perception and plays a key role in beliefs, desires and decisions (De Sousa, 1990). Michael Stocker studies emotions from the perspective of ethics, moral psychology and psychoanalysis. He places emotions at the center of identity, life and value, and emphasizes the importance of social and emotional context for solving ethical dilemmas and conflicts (Stocker \& Hegeman, 1996).

Cognitive theories of emotion persuasively demonstrate the cognitive ability of human's emotions, but there are still some questions with emotions needing further discussion. Firstly, the capacity of emotions of animals and infants is not resolved well in cognitive theories. As their arguments, each emotion contains corresponding evaluative judgments as its contents of intentionality. That means making appraisive judgments requires the ability of mind, but the possibility that animals can make appraisive judgments has be excluded in according to the requirement of the content of intentionality of emotions in the cognitive theories (The Stoicism and Descartes directly deny that animals have the ability of mind), therefore animals do not have the ability of emotions. As similar as animals' deficiency, infants do not have self-awareness nor the abilities of linguistic and thinking yet, so they can't make evaluative judgments in infancy. Reasonably, we can infer that infants do not have the ability of emotions. But these conclusions are not consistent with our daily experience; anyway, neoJamesianism's explanation about this topic is 
more rational.

The second query is that sometimes an emotion is triggered without sufficient or corresponding appraisive judgments as the contents of an emotion. Why does it happen? Let us go back to the case of encountering a Komodo dragon, now the Komodo dragon is locked in a firm building with thick concrete ceiling, walls and one transparent anti-collision glass curtain wall only in the front side for observing. When the visitors look at the monster face-to-face across the glass curtain wall, they believe (or judge) that they are absolutely safe and there is no any danger. Logically, the emotion fear should not be triggered in terms of the cognitive view that the contents of evaluative judgments are the triggering causes for an emotion. But disappointedly, most of the visitors still feel the emotion fear.

In order to remedy the above problems, some cognitivists try to relax the criterion of the content of intentionality in an emotion and accept perception without judgments or belief as the basic causing factor of an emotion. That is indeed tricky, because perception also involves cognitive activities while it does not contain the contents with judgments or belief, which are not necessary nor inevitable. After that theoretical adjustment, the ability of emotions of animals and infants is explained well. Whether the change can resolve the query that an emotion is triggered without sufficient or corresponding appraisive judgments as the contents of an emotion? However, it is a little doubtful, because perception has only limited cognitive functions and relatively narrow cognitive scope, for example, perception cannot reach to those cognitive activities involved judgments, deduction or thinking, etc., and the perceived contents are often too insufficient to trigger an emotion. It is inadvisable if one insists that the emotional effects of perception are completely equivalent to those of emotions caused by appraisive judgments, because that means we impose the contents of judgments on perception. In the example of Komodo dragon, It is not impossible that on the one hand a visitor makes the conclusion with the judgment (or believes) that he is absolutely safe when he look at the gigantic lizard across the thick anti-collision glass curtain wall, on the other hand he would perceive the view that the monster is dangerous and then experience the emotion fear, because one can perceive the shape, the location and the distance of the lizard, but he cannot perceive that the monster is dangerous; if he has already realized the danger of the gigantic lizard, actually he has reached to the cognitive level with judgments and reasoning and has made a conclusion. Anyway, it is back to the starting point of the problem, the replacement of evaluative judgment with perception has not been fully successful.

In addition, the cognitivists neglect another question: Do the evaluative judgments as the contents of an emotion occur because of the emotion by itself, or are they thoroughly another cognitive activity in company with an emotion? If the evaluative judgments are only the result of other cognitive activities in accompany with an emotion, then it is difficult to explain that emotions have cognitive function. And if the judgments are generated directly because of emotions by themselves, then that may result in the debate of human is and ought (factual proposition and value proposition); we could ask, whether or how does the actual state of the involved object lead to the evaluative judgments when a person faces an object? If the involved object has never existed in the world before, and humankind has no any 
knowledge about it, how can the person infer the evaluative judgments as the contents of emotions merely from its existence of the newcomer? What we discussed just now is related to the foundation of the cognitive emotion theories, but the cognitivists have not demonstrated about that theme further.

In recent years, other scholars, such as Andrea Scarantino and Paul Griffiths, propose the situated theory of emotion. They argue that emotions, which are triggered by the appraisive judgments as cognitive contents, have biological and genetic basis, and that social culture also plays an important role in the formation and development of emotions. And they suggest that we should expand the study of emotions to more fields, besides the research of neural network and conceptual thought, we should especially concern ourselves with the social and cultural environments in which emotions are moulded (Griffiths \& Scarantino, 2008). Being situated shows the interaction between emotion and cognitive activities. The theory is a good complement to explain the cognitive ability of emotion.

\section{Conclusion}

The discussion about the cognitive ability of emotion in traditional philosophy is fragmentary, there are only a few of terms and rough analysis. Neo-Jamesianism thinks physiological conditions determine emotions, and denies that emotion has cognitive ability. The cognitive theories of emotion advocate that emotion origins from evaluative judgment which is the result of cognitive activity. It is laudable that cognitivists support rationality of emotion and the ability of cognition of emotion. And the theories can meet most of the daily emotional experi- ence. But cognitive theories cannot well explain the capacities of emotions of all animals and infants. Also, sometimes the evaluative judgment in an emotion is not related to the trigger of an emotion. I agree with their assertion that emotion has cognitive ability, and also think simultaneously that the basic framework of an emotion is physiological and genetic but the content of an emotion is cognitive.

From the ontological angle, we can find that experiencing is the most essential activity of human beings, cognition as the unfolded understanding and emotion as the fulfillment of attitude to action are just different ways of experiencing. One person is always interacting with the nature, other persons and the self, which together provide a complex context in an interwoven way, so he always experiences everything around him or in him and even he becomes a part of being situated. He is constantly in cognitive activities, certain emotional state, and different actions. Understanding with cognition, appearing with emotion and acting with action, they function together in the context of the embedded interaction between the nature, society and self.

\section{REFERENCES}

Aristotle (2005). Rhetoric. (L. Niansheng, Trans.). Shanghai: Shanghai People's Publishing Press.

De Sousa, R. (1990). The Rationality of Emotion. MIT Press.

Descartes, R. (2015). The Passions of the Soul and other Late Philosophical Writings. Oxford: OUP Oxford.

Elster, J. (2012). Emotional Choice and Rational Choice. In P. Goldie (Ed.), The Oxford Handbook of Philosophy of 
Emotion. Oxford: Oxford University Press.

Goldie, P. (2002). The Emotions: A Philosophical Exploration. Clarendon Press.

Graver, M. R. (2007). Stoicism and Emotion. Chicago: the University of Chicago Press.

Greenspan, P. S. (2014). Emotions and Reasons: an Inquiry into Emotional Justification. Taylor and Francis.

Griffiths, P., \& Scarantino, A. (2008). Emotions in the Wild: The Situated Perspective on Emotion. In P. Robbins, \& $\mathrm{M}$. Aydede (Eds.), The Cambridge Handbook Of Situated Cognition. Cambridge: Cambridge University Press.

Hume (2015). Treatise of Human Nature. Andesite Press.

Kant (2005). Anthropology from a Pragmatic Point of View. (D. Xiaomang, Trans.).
Shanghai People's Publishing Press.

Lazarus, R. (1991). Emotion and Adaptation. Oxford University Press.

Nussbaum, M. (2001). Upheavals of Thought: the Intelligence of Emotions. Cambridge New York: Cambridge University Press.

Plato (2003). The Complete Works of Plato. (Vol. 2). (W. Xiaochao, Trans.). Beijing: People's Publishing Press.

Solomon, R. C. (1988). On Emotions as Judgments. American Philosophical Quarterly, 25(2), 183-191.

Solomon, R. C. (1993). The Passions: Emotions and the Meaning of Life. Hackett Publishing Company.

Spinoza (1997). The Ethics. (H. Yi, Trans.). Beijing: Commercial Press.

Stocker, M., \& Hegeman, E. (1996). Valuing Emotions. Cambridge University Press. 